\title{
The Management and Leadership in Regional Public Authorities of the Kaliningrad Region: Sociological Aspects
}

\author{
Vladimir V. Krivosheev* \\ Sergey N. Makarov \\ Immanuel Kant Baltic Federal University, Russian Federation \\ *Corresponding Email: krivs48@rambler.ru
}

\section{Doi:10.5901/mjss.2015.v6n6s7p190}

\begin{abstract}
Current article considers leadership problems of executive authorities of the Kaliningrad region. Leader management on the basis of the reformative concept of leadership is analysed. Interactions of heads with employees it was considered on four channels of influence: the individualised attention; the inspiring motivation; intellectual stimulation; charismatic influence. During the conducted research all respondents emphasise the importance of the factors stated above though also some features of perception of leadership skills of heads depending on age of workers, gender accessory are recorded.
\end{abstract}

Keywords: leadership, public authorities, Kaliningrad region

\section{Introduction}

For the present stage of development of the Russian society, the quality and efficiency of public administration are of the extremely essential practical and therefore cognitive importance. The continuous increase in the density of social time, and therefore complication of the solved problems, the need for rapid response to the changing situation in the on-line mode, sometimes very negative and critical, set ever greater requirements to the design and implementation of administrative decisions and the level of the professionalism of those who provide the authoritative influence on social processes. It thus comes to characterisation of the subject of management represented, in particular, by the leaders and all the employees of the executive branch including the regional level.

The article analyses the results of the sociological research that we conducted, in particular, in the Kaliningrad region, and dedicated to the consideration of leadership issues in the executive branch. Officials of the executive authorities (experts) were interviewed anonymously by questionnaires, quota sampling and the selective collection of 117 various categories of employees. The research was conducted in March-November 2014.

The research was mainly aimed at identifying leadership qualities of the chiefs of executive agencies and their skills in applying various methods of exerting influence on employees. We differentiate the concepts of 'management' and 'leadership'. Management is considered by us as a certain status characteristic of a member of the team due to the hierarchical nature of construction of the social institutes and assuming the right to govern. Leadership is defined as referential for a social group by qualities inherent in the personality of a leader. Thus, the management can be characterised as an objective quality of the management system to a large extent, and leadership is its property representing a subjective connotation. It is obvious that these two components are closely linked with each other, and taking into account the specifics of the national mentality and managerial traditions, leadership is of particular importance in terms of both the quality of the interactions in the management system itself and from the point of view of its interaction with the managed objects.

\section{The Sociological Aspects of Regional Governance}

In developing the programme and the choosing research instruments, the transformative leadership model proposed by Bass and Avolio (1994) was used. This model is known to consider the interaction of chiefs with the staff by four channels of influence, i.e. individualised attention; inspirational motivation; intellectual encouragement; charismatic impact. The model is optimal from the point of view of the phenomenon of managerial and intra-organisational interactions. Besides, its empirical expediency is determined by the convenience of isolation and operationalization of the indicative structures 
with the possibility of further verification. The model can also help visually identify the most vulnerable aspects of interaction through the 'leader - subordinate' line and thus optimise it.

The research results showed that all respondents had stressed the importance of the factors mentioned above (it should be noted that, according to the structure of tools, the factor was considered as the most significant one the average value of which is smaller). It was found that there the opinion about leadership of the people who are subordinates and the people vested with governmental authority were different. It appears to be quite obvious. But it is worth furnishing scientific proof in support of the fact (see fig. 1).

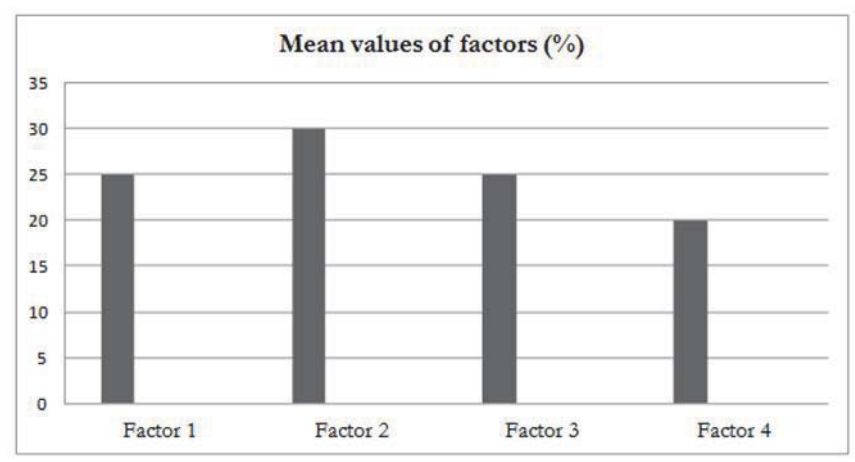

Figure 1. Distribution of the leadership component in management in order of importance

Note: Factor 1 - individualised attention; Factor 2 - inspiring motivation; Factor 3 - intellectual encouragement (stimulation); Factor 4 - charismatic influence

By focusing on the head's ability to seek from the head of the subordinate super efforts to achieve the organisation goals, respondents emphasised the component of management, which is regarded by researchers as something given to a person by nature (Berne, 2003).

When the management activities are considered from the standpoint of the object of management, bringing the 'inspirational motivation' factor to the forefront can be regarded as perceiving the manifestations of the charismatic properties of the head by his/her subordinates, that means determining the position of leader and followers to be similar in this case. The 'inspirational motivation' factor is interpreted as a method of control based on the employees' believing in the need for the activities; and the charismatic influence is based on the group personification of employees at the team-building stage (Glushchenko \& Glushchenko, 2000).

When leadership is under consideration, researchers often do not take into account the gender identity of employees of the management system. This is largely due to those stereotypes that are in the public mind with respect to women managers. It can now be stated that the stereotype is blurred as women increasingly hold leadership positions in organisations, and the structure of executive agencies is no exception. To more clearly present the dependence of factors on the gender specifics of the interviewed employees, the analysis was performed by a comparison of equivalent categories (factors) based on the average values of dependencies. According to the scale of indicator values and degrees, respondents chose one answer, in which the maximum expression of the factor (greatest significance of a feature) was one, and the minimum expression (lowest significance level) was five.

When the personalised attention category and its dependence on a gender are in question, there is a trend in the answers of respondents that the factor is mainly preferred by men (the average value of the feature is 2.00 ). Women are of the opinion that taking into account the strengths and weaknesses of employees, demonstrating interest towards others and developing the bilateral exchange of views are not an important term in the leader-based management. In our view, this state of things confirms the need for taking the fullest possible account of the specific situation in exerting the managerial influence as well as the importance of a strictly graded approach demonstrated by the head.

The second factor that has been proven to be important in the 'leader - followers, subordinates' relationships is manifested in the leader's ability to inspire optimism and enthusiasm in his/her subordinates. It turned out that women and men had demonstrated the same results (Table 1). 
Table 1. The dependence of leadership-based management factors on the gender characteristics of the respondents

\begin{tabular}{lccccc}
\hline & \multicolumn{5}{c}{ Values of factors } \\
\cline { 2 - 6 } Gender & & $\mathrm{f} 1$ & $\mathrm{f} 2$ & $\mathrm{f} 3$ & $\mathrm{f} 4$ \\
Male & & 1.90 & 2.13 & -2.26 \\
Female & +2.00 & & 1.90 & 2.17 & +2.28 \\
\hline
\end{tabular}

The intellectual encouragement factor, as already noted above, does not assume any significant attitude in the opinions of either specialists or experts. In the meantime, the trends, which the factor gets when viewed in the gender context, make it possible to make the following conclusions. Men (specialists and experts) believe that there is no need for the head to pay attention to a kind of intellectual support to subordinates; and male leaders are more emphatic about this than male subordinates, the mean values of male experts are 2.57, and the mean values of male specialists 2.13 (Table 1 ). Women give more preference in respect of this factor, both leaders and ordinary employees.

The charismatic influence of a leader demonstrates heteropolar priorities on the part of experts and specialists and correlates with the gender differential as follows (Table 1). However, the trends in the dynamics of this management factor have some differences. Male leaders demonstrate a clear trend towards an increase in the influence of a charismatic leader on the staff; the female heads perceive the heads with charismatic features the same as the heads without any charismatic features (Table 1 ).

Age is another characteristic, which is of great importance when considering the management system. Of course, humans develop certain age stereotypes as to how they perceive others during the social engagement (Massionis, 2004). In this situation, the management process is no exception. According to the research programme, sampling based on age was divided into five groups (1 - younger than 30, 2 - 30-39, 3 - 40-49, 4 - 50-59, 5 - 60 years old).

In the answers of the responding ordinary employees, the following trend is worth noting. There is a persistent decrease in the mean values of any feature (the charismatic influence etc.) with the increase in age of the respondents. If respondents of the first age group have mean values of 2.23 , in the fifth age group this factor has a mean value equal to 2.0 (Table 2). This suggests an increase in the importance of the individualised attention factor in management that includes promoting the independence of employees, the head's expression of interest in their well-being, the expansion of individual employees' freedom of action associated with the increased age of the respondents. The older the respondents, , on one hand, the more they appreciate the attention to them by the head, on the other hand, for older subordinates any excessive interest in them would be quite unwelcome. The relationship between the individualised attention and age in the responses of experts, i.e. operating managers, is quite different. Informative are the data represented with the coded age groups 1, 4 and 5. (Table 2). It is remarkable that young managers believe that the effective management is not related to the manifestation of attention to subordinates.

Table 2. The dependence of leadership-based management factors on the age characteristics of the respondents

\begin{tabular}{|c|c|c|c|c|}
\hline \multirow[b]{2}{*}{ Age } & \multicolumn{4}{|c|}{ Values of Factors } \\
\hline & f1 & f2 & f3 & $f 4$ \\
\hline Younger than 30 Years Old & 2.23 & -2.00 & +2.19 & 2.33 \\
\hline 30-39 Years Old & 2.17 & -1.90 & 2.30 & 2.30 \\
\hline 40-49 Years Old & 2.17 & 1.90 & +2.00 & -2.34 \\
\hline 50-59 Years Old & $+1-2.00$ & +1.70 & +2.00 & -2.29 \\
\hline Over 60 Years Old & $+/-\quad 2.00$ & 1.90 & +2.01 & -2.28 \\
\hline
\end{tabular}

The importance of the inspiring motivation factor and its relationship with the age characteristics are also essentially different in the employee and expert surveys. Ordinary representatives of the management systems prefer the emotional mood of their teams and demonstrate not so many differences in the assessment of this factor depending on age. (The data presented in Table 2). Young managers do not lay special emphasis on the team's emotional mood, and this focus will intensify with the increase of years but only up to a certain limit, i.e. fifty years. From this age limit the inspiring motivation factor is becoming increasingly important for managers.

The intellectual encouragement factor by the influence priority level is determined by respondents as the least important. When the survey data of the rank-and-file employees are reviewed, and in the case of a motivational factor, there is a tendency of low differentiation of the feature in correlation with age categories. The average values of the relationship between the intellectual stimulation factor and the age of the interviewed managers, on the contrary, can be 
characterised by a great variety (Table 2). Young managers assign high priority to this component of management, and the mean value of their responses is 2.27. However, with advancing age, managers do not consider it necessary to encourage creativity among their employees, and the average value of the feature becomes 2.63 . The average age of managers is around forty years, so this trend cannot but cause concerns about demonstrating a creative approach in the activities of the employees who represent the executive authorities.

It is rightly pointed out that if the head has some charismatic features, the leader can operate most effectively (Tolochek, 2000). It is no coincidence that the responding managers give preference to this factor. However, it should be noted that the value of this category is changed depending on the age (Table 2). Young managers and managers at the age of sixty years and older give maximum preference to the charismatic influence. Managers of the middle age (the second and the third age groups) demonstrate the highest managerial pragmatism.

\section{Conclusion}

In conclusion, it can be stated that leadership is not only an important tool for improving the quality and efficiency of management but is also quite a variable construct within the organisational space of public authorities. This position allows us to consider the leadership characteristics of the head as an important form of interactions that need to be considered not only in the context of the continuing self-socialisation of a manager but also during the development of appropriate training and retraining programmes for them. It is for this reason that the time is ripe for a significant change in the role of educational institutions that deliver training to civil servants. This could be the preliminary establishment of a specific organisational environment to shape managerial human resources instead of just transferring some knowledge.

\section{References}

Bass, B.M., \& Avolio, B.J. (1994). Improving organizational effectiveness through transformational leadership. Thousand Oaks, CA: Sage Publications.

Bern, E. (2003). Leader and Group: translation from English. Yekaterinburg: Litur.

Gluschenko, V.V., \& Gluschenko, I.I. (2000). Research into Management Systems, Sociological, Economic, Predictive, Experimental Research. Zheleznodorozhny: Krulya.

Massionis, J. (2004). Sociology. 9th edition. SPb.: Piter.

Public Service of the Smolensk Region (2004). Almanac. Issue 4. Smolensk.

Tolochek, V.A. (2000). Stylistic Characteristics of the Interaction of a Manager in the Management Structure. Organisational Psychology: Chrestomathy (pp 294-302). SPb.: Piter. 